\title{
Surfing the Mystery of J. C. Dawn's Ripple of Existence: A Stylistic Study
}

\author{
Sheline* and I Rifai \\ English Department, Faculty of Humanities, Bina Nusantara University \\ *Corresponding author email: sheline@binus.ac.id
}

\begin{abstract}
Existentialism is not a new concept to poets. As part of philosophical theory, existentialism is a concept built upon an understanding that human search for their own meaning in life, thus strive to make rational decisions in response to the world's phenomena. Generally philosophical, poets often ponder and write about their existentialism questions and thoughts into poems. Many of these existentialism themed poems, like those of Emily Dickinson, received favourable responses form the readers as they share the same existentialism questions and wonders with Emily. This paper presents an analysis of 11 poems from Mystery of Existence chapter in the Ripple of Existence book by J. C. Dawn, an Indonesian raising star poet who published her poems in English. The analysis was done in six stylistic levels of analysis: phonological, graphological, morphological, lexical, syntactic, and semantic levels. As the result of the analysis, the 11 poems rendered existentialism messages whose themes were reinforced by the styles of the language used.
\end{abstract}

Keywords: Surfing, J.C. Dawn, Mystery

\section{INTRODUCTION}

Man have been wondering about life, death, and life's meaning since the early dawn of their existence. As soon as they developed letters and other media to express themselves, man began to have means to channel their feelings, wonders and curiosities in the shapes of drawings, moving images, literary works, and many other art forms. As an art form that predates written texts [5], poetry is one of the popular literary expressions that has been used to channel man's or the poets' deepest thoughts. Authors like Emily Dickinson or Philip Larkin are known to have often expressed their existentialism thoughts and ideas in their poems.

Existentialism is an interesting theme to raise as this is a phase that many people deal with in their lives. As readers, people could easily relate to the writing of one's confusions, wonders, and the reasons of man being in the world. The theme frequently found poems produced by authors or poets in different periods of times. One of the poets that we recognized as having existentialism theme in her poems is an Indonesian poet who is based in Australia, J.C. Dawn. In 2019, she published a book titled Ripple of Existence. J.C dawn, whose real name is Jesslyn Tan, admitted that it was her passion in poetry, love of reading, and English language that motivated her to write poems in English.

The Ripple of Existence's book is divided into 6 chapters that have different subtitles, i.e., Mystery of Existence, Wisdom, Simplicity, Courage, Love, and Death. Based on a personal interview in 2020, J. C stated that her poems were aimed to reflect on and accept life's mystery, seek wisdom, embrace simplicity, cultivate courage, believe in hope and love, and face the certainty of death with less fear. In her book, J. C Dawn talked about existentialism in chapter 1 which is titled Mystery of Existence.

Having read the book multiple times, we (the authors) were keen to answer some inquiries. Firstly, we wanted to understand the existentialism concept found in the 11 poems. Secondly, we wanted to explore those messages by using the 6 level of stylistic analysis to know whether the language used by the poet weaken or strengthen the existentialism theme. The 6 level of stylistic analysis are phonological level, graphological level, morphological level, lexical level, syntactic level, and semantic level.

The theoretical tools used to support the analysis of the poems is based on the stylistic analysis of Gnanasekaran [1]. Stylistic is a branch of linguistics which studies the style used in literary and verbal language, and the effect writer wishes to communicate to the readers. In doing the analysis, this study was guided by two questions, i.e., what are the existentialism messages found in the 11 poems? And how do the 6 level of stylistic analysis reinforce or weaken the existentialism theme?

\section{EXISTENTIALISM AND THE STYLISTIC ANALYSIS OF POEM}

Existentialists' questions usually revolve around individual's experiences, thinking, and feeling on 
life [4]. It is closely related with man's situation, understanding, and responses to whatever life has to offer. A well-known philosopher of existence is Jean Paul Sartre. The principle of existentialism by JeanPaul Sartre is that "Man is nothing else but what he makes of himself". The essence of us being in the world is made by the existence in individuals' life, in addition to "what you do shapes what you are" [4].

The next concept of existentialism is an idea called dasein. The philosopher of dasein is Martin Heidegger. According to Heideggar, the ways to understand things come from the point of views of human being and person engaged with the world living. For instance, individual's experience in living the world at every moment by using term dasein (being there or being here) [4]. The proverb of dasein is "how I experience myself in the world, certainly world is a part of dasein".

In addition to dasein concept, there is another concept introduced by Soren Kierkegaard. Many people suggest that angst concept is similar to fear. To underlie, Angst concept is not the same as fear concept. Fear is the situation which frightens and lead somebody to avoid the objects whereas Angst is sense of being anxious, feeling not at home and things not being right. The illustration of angst is the way of people want to escape from it [4]. Another concept of existentialism is the concept of cogito ergo sum, which was introduced by Rene Descartes. Rene Descartes is French philosopher who describe cogito ergo sum concept as "I think therefore I am" [4].

The existentialism concepts as explored above are often found in literary works. Thus, poem analysis is often done by going deep with the two elements: intrinsic and extrinsic elements. Intrinsic element is element that influence a literary work's creation [2]. Extrinsic element is the elements located outside of literary work but influence the existence of literary work as creation [2].

In order to explore literary work, scholars of the field have used different approaches. One of them is stylistic analysis. Stylistic is a branch of linguistics which studies the style used in literary and verbal language, and the effect writer wishes to communicate to the readers. It is also the study of the way author uses words and grammar within the sentence and text. There are several definitions of stylistic based on figures Geoffrey Neil Leech (1964). Geoffrey Neil Leech stated stylistics is the study of literary style. The focus stylistic is text and setting out to discover the 'rules governing' the process by which linguistic elements and patterns in a text accomplish their meaning and literary effects
[1]. The stylistic analysis of 6 level language is phonological level, graphological level, morphological level, lexical level, syntactic level, and semantic level [1].

\subsection{Phonological Level}

In phonological level, stylistic analysis contains of phonetic sounds [harsh consonants $(p, b, t, d, k, g, t S$, $d Z, f, v, \theta, T, s, z, S, Z, h)$, soft consonants $(m, w, n, l$, $N, r, j$ ), monophthongs (I, i:, e, A, $\Lambda, E, 3:$ a:, b, o, v, $\mathrm{u}$ :), and diphthongs(el, al, ol, Ev, av, IE, eE, $v E)]$. The phonological level also analyses rhyme (repeated sound at the end of sentence) and assonance (the repeated vowel sounds in multiple words of lines) [6].

\subsection{Graphological Level}

In graphonological level, stylistic analysis contains of font type and font size used in the written of text. It also analyse the whole things in the written text (lines and stanzas). For instance, indentation (the space at the beginning of a written line or paragraph), alignment (the position of arrangement in the lines of text), line spacing (the space between words in the sentences), capitalization of words, total of stanzas and lines, title design (catchy or simple), punctuation (the use of spacing or other signs), and the putting media on [mise-en-page (page) or miseen-ecram (screen)] [6].

\subsection{Morphological Level}

In morphological level, stylistic analysis contains of compounding (joining two or more primary words), coinage (invention of new term such as names of one company's product), derivation (create new words in changing or maintaining of prefixes and suffixes), and inflection (create new words that maintaining suffixes) [6].

\subsection{Lexical Level}

In lexical level, stylistic analysis contains of common words used in the poems by using voyant tool. It also analyse the cohesions (the way of sentences hold together by using connections between the ideas within in the text) discusses two kinds cohesions: grammatical cohesion and lexical cohesion [3]. Grammatical cohesion discussed in this paper are reference (word or phrase that can be determined by referring to other parts of text), conjunction (meaning related to the use of cohesive device in the text), ellipsis (the use of zero or an outright omission), and substitution (to avoid the use repetition in the text). Lexical cohesion is concerned with the relationship between words which have meaning, such as verb, noun, and adjective. It can be divided into reiteration (form of lexical cohesion used repetition, synonym, near synonym) and 
collocation (the relationship between items in the text such as hyponym and antonym) [3].

\subsection{Syntactic Level}

In syntactic level, stylistic analysis contains of structure of sentences (simple sentence, compound sentence, complex sentence, compound-complex sentence). It also looks at the use of parallelism (the repetition of identical structures), inverted word order (subject comes after the verbs in the sentences), and forms [active form (it performs the action) or passive form (it affected by the action)] used in text [6].

\subsection{Semantic Level}

In semantic level, stylistic analysis contains figurative languages, namely allegory (interpreted to reveal a hidden meaning), imagery (the object appeals to our physical senses through 6 imageries), irony (occurs when what actually happens turns out to be completely different from what would be expected), metaphor (compare two things differently means something different from literal), oxymoron (pairing two words together that are opposing), personification (idea is given human attributes and/or feelings as if it were human), simile (comparison typically contains of like, or), and synecdoche (the word uses to refer the whole sentence) [6].

\section{METHOD}

The method used to analyse this paper was qualitative analysis by using stylistic analysis. The material of the poems is Ripple of Existence book by J. C. Dawn. We did not analyse all chapters in book, but we focused more on chapter 1 that had Mystery of Existence as the explicit theme. The focus of the study was to analyse the 6 level of stylistic analysis used in Mystery of Existence poems.

In the first step, we decided to choose 6 level of language as the main topic. After that, we found the suitable literary work for that topic. The selected literary work was Ripple of Existence by J. C. Dawn. We decide to choose poems in chapter 1 of Mystery of Existence for analyzing the data because it seemed that existentialism issues was mostly expressed.

We read the 11 poems in the chapter multiple times and discussed them before going deep with the analysis. As previously mentioned, we analyzed the poems by using stylistic theory. In stylistic analysis we integrated 6 level of languages in the poems to find the existentialism messages and whether the language used reinforced or weakened the existentialism theme.

\section{RESULTS \& DISCUSSION 4.1. The existentialism messages found in the 11 poems}

Message is something that most authors want to deliver to the readers. Having semantically analysed the 11 poems, we found existentialism messages in the 11 poems that were based on existentialism concepts. These are the messages or concepts found in the poems. In this subsection, we mostly used the pragmatic and semantic levels of analysis in order to interpret the messages that the 11 poems wanted to deliver.

\subsubsection{Existence Precedes Essence.}

It means that every human being is responsible for their own actions and life choices. In poem 2, "We" as the persona in this second poem of stanza 2 refers to the people living in the field of art. The author used the term scientist to acknowledge their expertise level of the field and put the resemblance to what they do in arts with those that scientists do in science. In stanza 3, when the author used the sentence, "uncertainty is a beast that when kissed, becomes a charming tale," the author put the emphasis on the word "uncertainty" and how as man we should respond to it. He advised, implicitly, that we treat it as a thing that we need to treasure, thus we "kiss" it. Because once we do it and treat it more positively, it will turn into something more pleasant, or in the author's phrase, "a charming tale".

In poem 4 of stanza 2 , when the author used the sentences "inside the confinement there is freedom, inside the pain there is joy, and inside of art there is truth," showed the author's optimistic and positive attitude toward life. She believed that after all the difficult things in life, lie happiness. In stanza 2, when the author used the phrase "art is not fictional sentence", she wanted to emphasize that art is a real thing. It also means that it's a part of the reality of the author's existence who was freed by art. In the next, art likes the tool to get existence of freedom based on existence precedes essence concept.

In poem 6 of stanza 1, it pictures two men in "he" and "boy". As metaphors for a dilemma or choices that she had to deal in life. He was described as a person who wanted to be a cool person by having expensive car (sports car). The kind of person that chose to exist over being true to himself. On the other hand, the other persona, "a boy" offered a different perspective. The phrase "eyes deeper by the sea" is a figurative language that the author used to mean that she would such essence than existence. 


\subsubsection{Dasein.}

It is the concept of "man being in the world" and "being there" in the world. In poem 5 of stanza 1, it explains about the date and time that occur in the life of the author. The author questioned his position, his being, in the society that lacks social interactions. In stanza 2, "we either stay in different yesterday - or dream of different tomorrows refers to the antonym" talks about the feeling of being in the void, in a space where nothing seems to happen - no channels communication is open between man with the authors or man with other man. In stanza 3, timeless and pace less space that resembles the "void" that the author stated in stanza 2. In the void, the author used the word "beast" to describe man's situation to represent trapped emotions that have no place in the space.

In poem 1 of stanza 1, "we" refers to the people live in this world. The poet emphasized her existence in the universe and saw life as a whole. It cannot separate between "stars and night "and "I and universe."

The poet also saw wonderment in the bleakness of the mortal realm, constancy in the dynamism of life, and harmony in the chaos of being. In the stanza 2, when the author wrote, "life cannot be subjective and objective at the same time," it refers to the ways that she struggled to understand the viewpoints and the factual points or approaches that she encountered in life as perhaps, a student. Furthermore, despite her struggle to understand, she expressed a rhetorical question on the significance of understanding little things than to misunderstood a lot.

In poem 7 of stanza 2, "you" is used as the person that resembles the moment before the music ends, a moment of comfort. After its end, other things come to continue. It is the same as life. In life, there is past situation and future situation occurs. In the stanza 3, the poet experienced the situation from and your touch that was once warm turn my lung into ice into the sun will shine and flowers grow on the tiny pieces of my soul that you tore. It is dasein concept of "how I experience myself in the world." These situations occur in every individual's life. Sometimes people experience these situations. People experience up and down in their lives. And it will go, and we will all become the transition to that perpetual changes, according to the poet.

\subsubsection{Angst.}

It is concept of the sense of being anxious and things not being right. In poem 3 of stanza 1, one twinkling star to beautify a sky. It describes how the sky would only need one twinkling star to light it up. In the poem, losing in despair proves the condition of complete loss or absence of hope. It is a similar concepts of angst or being anxious. The author meant that nobody should feel despair despite their little contribution to the society. In stanza 3, she continued to encourage by writing, "you are hope, endurance, human". People can light its surrounding like a star by believing they are important to this world, like the light of star can light the world to be shine inside the darkness, like a light.

In poem 8 of stanza 1 , the poem revealed the feeling of drained and lonesome. Being drained and lonely are the tiring conditions used in the poem. It is the same as angst concept. The author struggled to explain the world as a sacred place. Meanwhile, some other people see the world as a game (place to play). The game is also something competitive with each other. In the game, there are winners or losers. In stanza 2, the continued by asking, "it is matter if we lose or win?" In this life, the oxymoron of losing and winning appears to complete this life. The author belittled the concept of competition in life when she asked, "what does it matter If we lose or win?"

In poem 10, it begins with the many settings occurs in the life. The settings are morning and evening settings. Gentle breeze describes the weather of windy in the morning, sunlight that flickers through bare branches describes the hot weather in the noon, sun over horizon describes the sun is above in the afternoon day, and close with warm and silent flow of night before you sleep describe the night situation. In the last stanza of poem 10, the sentence contains of existence is would you find me? Would you find me in the most silent spaces of your being? The existence in the most silent spaces appear in the poem. In the silent spaces, it is difficult to find the existence of people. The existence of individual person still ambiguous. It is contains as angst concept. The question of existence of individual person still cannot answer properly.

In poem 11 of stanza 1 , it can compare between river and time. The time always rotating from time to time like flowing the river. It influences changing people mind' feeling (clouds of my mind). Thoughts and feelings are the two things owned by individual people. Those things are meaningful and empty. It is same as angst concept. Sometimes all are meaningful and sometimes all are empty. Empty refers emptiness of heart (feeling). Besides, poet thinks home is an illusion. Illusion refers to something not real, not exists in this world. Home also not a place but it is twinkling star in the sky. It is light. In silence, she whispers secrets and tells me 
the truth. She refers to universe. In the end, I understand that I just am (myself) no other self.

\subsubsection{Cogito Ergo Sum.}

It is related to mind and body used in the poems. In poem 9 of stanza 1, It is related to cogito ergo sum concept of mind and body. It shows that mind and body have a relationship to continue living this world. For instance, body engages us with a real world whereas mind with transcendence. This body is real owned by every individual live whereas mind is something beyond the visible limit. Individual person prefer to like mundane things such as Ferraris (luxury things) and flawless skin (beauty) rather than stars (specks) in the sky. In stanza 2, this body is reified yet alien place to live in. It feels foreign for human no other creatures. It likes the sky meets the sea that is where you will find me.

\subsection{The existentialism issue in the Mystery of Existence chapter: Reinforced? Or Weakened?}

\subsubsection{Phonological Level.}

In writing this poems, poets uses several phonetic sound such as harsh consonant, soft consonants, monophthongs, and diphthongs. The poet also uses assonance (the repeated vowel sounds in multiple words). The use of assonance is to make the sentence in poems more beautiful soundly. The rhyme sound used in the poem is not rhythmic because it does not have the same repeated sound at the end of line. This rhyme is called as free rhyme. It makes the poets freely to choose the words in the lines.

\subsubsection{Graphological Level.}

It uses Garamond font and $11 \mathrm{pt}$ for font. It also uses left align (to make the position of lines in poems left align) whereas the line spacing used in the poems is 1.5 lines (the space is suitable to her poems; not too near or too wide between lines). The left align makes the written text can be easier to read and to give empty space for some illustration or picture which describes of poems. It is called as mise-en-page which discusses about the design of printed pages, including the layout of the text and illustration used by the poets. Besides, the stanzas used in the poems have many variants from 1 stanza until 6 stanzas and the lines come from 6 lines until 25 lines. The title design used in the poems is simple (easy to understand and not using difficult words). Moreover, the poems also used the initial capitalization in starting the sentences in the poems. In the next, it also uses several punctuations (question mark, single quotation, comma mark, full stop, semicolon, apostrophe, exclamation mark) in the poems.

\subsubsection{Morphological Level.}

In morphological level, the poets uses 4 methods: compounding, coinage, derivation, and inflection. In compounding, it founded the combination of noun and noun (lifetime) refers to length that somebody is alive, combination of adjective and noun (somewhere) refers in, at, or to an unknown or unnamed place, and combination of verb and noun (interwoven) refers to twist together or combine two or more things so that they cannot be separated easily. In the coinage, we found the words of Ferraris which is refer to Italian luxury sport car manufactures. The use of coinage is to represent basic word of brand (Ferraris) rather than the things (car).

In this poem, it can be found the derivation of class changing suffix and class maintaining prefix. Wonderment is the combination of wonder and ment (suffix). Wonder (verb) is feel curious of something whereas wonderment (Noun) is a state of awed admiration or respect. Misunderstand is the combination of mis (prefix) + understand. Understand (verb) is to know or to realize the meaning of words whereas misunderstand (verb) is fail to interpret or understand something correctly. Inflection is the process of creating new words in maintaining by using suffixes. These are the words of class maintaining suffix such as the words still maintaining Noun as the parts of speech (wholeness, stars, eyes, things, concepts), the words still maintaining verb as the parts of speech (breaking, defining, equations, twinkling, points), and the words still maintaining adjective as the parts of speech (nobler, charming).

\subsubsection{Lexical Level.}

In this poems, the total words founded are 262 words. The most common word used by author in this poems are life which is repeated for 6 times. Life word has a relationship with existentialism theory. It represents the individual person in the life. The author uses life to state life as the wholeness situation. Wholeness (noun) refers to the state of forming a complete and harmonious whole (the unity). Unity and harmony are parts of illustration of individual life. Every individual experiences this situation of life. It cannot separate from individual.

The poems also use cohesion such as conjunctions, ellipsis in writing the poems. The use of conjunction is to connect the two clauses into one complete sentences. For instance, we think we are running somewhere, but really we are just floating in our own void (coordinating conjunction), it is like being heard after a lifetime of silence (subordinating 
conjunction), and We either stay in different yesterdays - or dream of different tomorrows (correlative conjunction). Moreover, the use of ellipsis by poet is words are omitted from the sentence because everything is clear by the surrounding of text. Ellipsis founded in the poems are textual ellipsis and subject pronouns. Can we divide 'I' from the Universe, or the Universe from 'I'? is the example of textual ellipsis. In this sentence, it omitted the same repetition of can we divide because to prevent unnecessary in making long sentence. The example of subject pronouns ellipsis is every time I close my eyes and see this truth with my heard, it is like being heard after a lifetime of silence. The subject pronoun in this sentence is it refers to this truth

\subsubsection{Syntactic Level.}

The written poems can divide into several types of structure of sentences, namely simple sentence, compound sentence, complex sentence, and compound-complex sentence. The use of structure of sentences is to make complete sentence which is divided into at least have one subject and one verb for simple sentence. For instance, I see wonderment in the bleakness. The subject in this sentence is I, the verb is see, the object is wonderment, and the complement is in the bleakness (preposition+ determiner+ noun). In writing the poems, it also uses parallelism to make good in unite words within the sentences. It makes the poems easy to read by readers in repetition two or more similar structure. For instance, I see wonderment in the bleakness of the mortal realm; constancy in the dynamism of life; harmony in the chaos of being. It also found the use of inverted word order which is demanding some actions for subject to do it. For instance, can we separate the stars from night? The subject (we) comes in between 2 verb parts: can separate. The analysis of forms often used in the poem by author is active form. The use of active form is to indicate the subjects performs the actions (verb). For instance, every time I close my eyes and see this truth with my heart, it is like being heard after a lifetime of silence. The subject (I) performs the actions (close and see). In writing the poems, it uses the active form to make the sentence more strength and have clear descriptions.

\subsubsection{Semantic level.}

Semantic level is level of stylistic analysis which discusses about the meaning of words within the sentences in the poems. In allegory, the poems founded the several words which have hidden meaning such as alien and mortal realm. The meaning of alien in this poem is person who is not a citizen of the country in which they live or work whereas mortal realm is the place living for human or called as earth. In imagery, it founds several imageries to make the readers can imagine the objects through that imagery. In irony, it founds verbal irony such as beasts without a heart. Beasts is sarcasm because it included in low hierarchy before human world. In metaphor, it founded metaphor such as home is a twinkling star in the sky. It compares two things differently between home and star. In oxymoron, it founded the two pairs words used in the poems such as harmony and chaos. The use of oxymoron is to pairing the two opposite words into one sentence. The word of harmony and chaos are related to existentialism of human life.

In personification, it founded the idea such as changes clouds of my mind. This sentence is giving human attributes (mind) to the cloud. In simile, it founded the comparison by using like and as. For instance, it is like being heard after a lifetime of silence. It makes the comparison between it and after a lifetime of silence. In synecdoche, it founded words which refer to the whole such as spaces. For instance, would you find me in the most silent spaces of your being? Spaces is the place of human lives. Spaces describes the place of existence of human being to live and to stay.

\section{CONCLUSION}

The mystery of existence poems is related to existentialism theory of life. The approach of analysing the Mystery of Existence poems by J. C. Dawn is using stylistic analysis in 6 level of languages, namely phonological level, graphological level, morphological level, syntactic level, lexical level, and semantic level. The existentialism message found in the 11 poems were the messages of existence precedes essence, dasein, angst, and cogito ergo sum concepts. At the stylistic level of analysis, the lexical level and semantic level were two linguistic styles that predominated the styles of the language applied by the author. At the lexical level, the common words used to describe the existentialism issue is the repetitiveness of life's cycles. At the semantic level, the 11 poems used the figurative language such as allegory to reveal the hidden meaning of alien (human person), mortal realm, harmony and chaos as oxymorons, and synecdoche which contains spaces (the place of existence of human being to live and to stay) words. These two levels of stylistic levels alone reinforced the theme of existentialism in the chapter. 


\section{REFERENCES}

[1] Gnanasekaran, D 2018 A practical approach stylistics of poetry (Chennai: Notion Press) https://play.google.com/books/reader?id $=61 \mathrm{pODwAAQBAJ} \& \mathrm{pg}=$ GBS.PT22

[2] Setiawan, K E P and Andavani 2019 Strategi ampuh memahami makna puisi teori semiotika michael riffaterre dan penerapannya (Jawa Barat: Eduvision) https://play.google.com/books/reader?id $=$ SGndDwAAQBAJ\&pg=GBS.PA11

[3] Tamunobelema, D I 2018 The fact of cohesion and coherence in textual harmony British journal of english $\begin{array}{llll}\text { linguistics, } & 6 & 4 & 43-51\end{array}$ http://www.eajournals.org/wpcontent/uploads/The-Fact-of-Cohesionand-Coherence-in-Textual-Harmony.pdf

[4] Thompson, M and Rodgers, N 2011 Existentialism made easy: flash (UK: Hodder Education) https://play.google.com/books/reader?id $=$ Ne2jUxsx5-0C \&pg=GBS.RA1-P

[5] Joannou, A 2014 Poet goes from newsprint to verse http://www.yukonnews.com/arts/poet-goes-fromnewsprint-to-verse/

[6] Sharma, L R 2019 What to consider while executing stylistic analysis of a poem American research journal of humanities social science, $2 \quad \begin{array}{lll}\mathbf{1} & 11-20\end{array}$ https://issuu.com/arjhss/docs/b211120 